Editorial

\title{
Acknowlegement to Reviewers of Recent Progress in Materials in 2020
}

\section{Recent Progress in Materials Editorial Office}

LIDSEN Publishing Inc., 2000 Auburn Drive, One Chagrin Highlands, Suite 200, Beachwood, OH, USA; E-Mail: rpm@lidsen.com

Recent Progress in Materials

2021, volume 3, issue 1

doi:10.21926/rpm.2101001
Received: January 04, 2021

Accepted: January 04, 2021

Published: January 07, 2021

\begin{abstract}
The editors of Recent Progress in Materials would like to express their sincere gratitude to the following reviewers for assessing manuscripts in 2020 . We greatly appreciate the contribution of expert reviewers, which is crucial to the journal's editorial process. We aim to recognize reviewer contributions through several mechanisms, of which the annual publication of reviewer names is one. Reviewers receive a voucher entitling them to a discount on their next LIDSEN publication and can download a certificate of recognition directly from our submission system. Additionally, reviewers can sign up to the service Publons (https://publons.com) to receive recognition. Of course, in these initiatives we are careful not to compromise reviewer confidentiality. Many reviewers see their work as a voluntary and often unseen part of their role as researchers. We are grateful to the time reviewers donate to our journals and the contribution they make.
\end{abstract}

The editors of Recent Progress in Materials would like to express their sincere gratitude to the following reviewers for assessing manuscripts in 2020.

We greatly appreciate the contribution of expert reviewers, which is crucial to the journal's editorial process. We aim to recognize reviewer contributions through several mechanisms, of which the annual publication of reviewer names is one. Reviewers receive a voucher entitling them to a discount on their next LIDSEN publication and can download a certificate of recognition directly from our submission system. Additionally, reviewers can sign up to the service Publons

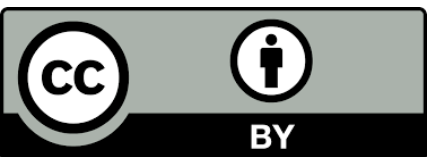

(C) 2021 by the author. This is an open access article distributed under the conditions of the Creative Commons by Attribution License, which permits unrestricted use, distribution, and reproduction in any medium or format, provided the original work is correctly cited. 
(https://publons.com) to receive recognition. Of course, in these initiatives we are careful not to compromise reviewer confidentiality. Many reviewers see their work as a voluntary and often unseen part of their role as researchers. We are grateful to the time reviewers donate to our journals and the contribution they make.

If you are interested in becoming a reviewer for Recent Progress in Materials, see the link at the bottom of the webpage http://lidsen.com/joinus.

The following reviewed for Recent Progress in Materials in 2020:

\begin{tabular}{|l|l|l|}
\hline Emmanouil Chatzipetros & Johann Michael Köhler & Julie Jin \\
\hline A. Ghosh & Heli Kangas & Sung-Kyu Hong \\
\hline Jeremy Goldman & Ana Catarina Trindade & Krzysztof J. Kurzydłowski \\
\hline Soroush Irandoust & Daniel Tay & Nikos Karayiannis \\
\hline Kelvin I. Afrashtehfar & Jaume Garcia-Amoros & Qingsong Yu \\
\hline Imane Belyamani & Ali Tamayol & Stanisław J. Kłosowicz \\
\hline Marco Erba & M. Pudlak & Felixberto A. Buot \\
\hline Tomislav Prokopec & Jan de Boer & Sartore Luciana \\
\hline James P.K. Armstrong & Carolina Londoño & Boris Schklovskii \\
\hline Chiara Bedon & F. Ascione & Nick Tovar \\
\hline María Isabel Rial-Hermida & Stephen Moratti & Shahin Homaeigohar \\
\hline Shiomi Kikuchi & Riccardo Spaccini & Jorge Carvalho Silva \\
\hline Pablo Arrighi & Maria Letizia Manca & Rudolf Roemer \\
\hline Małgorzata Lekka & Pablo Pou & Juan Francisco Olivera \\
\hline Barbara M. Maciejewska & Abraham J. Domb & Yogendra Kumar Mishra \\
\hline Nikunjkumar R. Visaveliya & Chunhui Li & Emre Araci \\
\hline Marta Kopaczynska & Saeed Miramini & Joerg C. Neuefeind \\
\hline Sayantan Choudhury & Iolanda Francolini & Rathinam Balamurugan \\
\hline Chris Moraes & Zois Syrgiannis & Florentino Borondo \\
\hline Justin L. Brown & Sahba Mobini & Marcos Garcia-Fuentes \\
\hline J. Alfaiate & Muhammad Jamil & Hae-Young Kim \\
\hline Burak Gerislioglu & Hani Salim & Serena Danti \\
\hline Marc-André Fortin & Eloi Pineda & Pierluigi Colombi \\
\hline Robert H. Hurt & Eleonore Fröhlich & Franz Brückert \\
\hline S. Bellucci & Woongkyu Park & Katarína Valachová \\
\hline Masaya Maeda & & \\
\hline
\end{tabular}




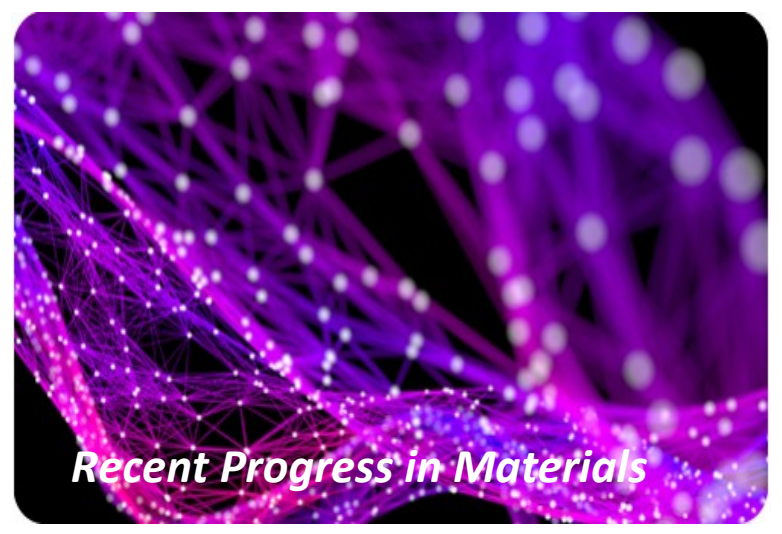

Enjoy Recent Progress in Materials by:

1. Submitting a manuscript

2. Joining in volunteer reviewer bank

3. Joining Editorial Board

4. Guest editing a special issue

For more details, please visit:

http://www.lidsen.com/journals/rpm 